\title{
Fetal Anomalies in Twin Pregnancies
}

\author{
${ }^{1}$ Tuangsit Wataganara, ${ }^{2}$ Katika Nawapun, ${ }^{3}$ Nisarat Phithakwatchara
}

\begin{abstract}
Twinning increases the chances of structural anomaly in the fetus. Discordance in physical development of the fetuses raises both ethical and management dilemma. Chorionicity plays an important role when selective feticide is an option. Anomalies found in singleton pregnancy can also be found in twins. Certain anomalies, such as acardiac fetus, are unique to monochorionic (MC) twin gestations. These anomalies may require in utero intervention to salvage its normal co-twin. Structural abnormalities, such as obstruction in fetal gastrointestinal tract resulting in polyhydramnios, can threaten the loss of the whole pregnancy. In MC twins, demise of the anomalous fetus can result in either demise or cerebral palsy of its co-twin. Fetal cord occlusion of the anomalous fetus can be offered to prevent these deleterious effects to its normal co-twin. Discordance of karyotypes in dichorionic (DC) twins is increasingly diagnosed in prenatal period. Selective feticide in this situation is simpler, but more ethical concerns are being raised. The technical and ethical considerations related to various kinds of discordance fetal malformations in the twin pair will be discussed in this review article.
\end{abstract}

Keywords: Chorionicity, Fetal anomaly, Twins, Twins reversed arterial perfusion sequence.

How to cite this article: Wataganara T, Nawapun $\mathrm{K}$, Phithakwatchara N. Fetal Anomalies in Twin Pregnancies. Donald School J Ultrasound Obstet Gynecol 2016;10(3):308-312.

Source of support: Nil

Conflict of interest: None

\section{INTRODUCTION}

Twinning is a complication that occurs in approximately $3 \%$ of pregnancies. The prevalence of twinning is on the rise due to a widespread use of artificial reproductive technologies (ARTs). Chorionicity is the major determination of pregnancy outcomes in twins. Pregnancy resulting from ARTs has an increased chance for both monozygotic and dizygotic twins. A majority of twins (approximately $70 \%$ ) are dizygotic. The chances of either anatomical malformations or genetic aberrations occurring in twins are higher than that occurring in the singleton at comparable gestational age. ${ }^{1}$ The

\footnotetext{
${ }^{1}$ Associate Professor, ${ }^{2}$ Lecturer, ${ }^{3}$ Assistant Professor

${ }^{1-3}$ Division of Maternal-Fetal Medicine, Department of Obstetrics and Gynecology, Faculty of Medicine, Siriraj Hospital, Bangkok Thailand

Corresponding Author: Tuangsit Wataganara, Associate Professor, Division of Maternal-Fetal Medicine, Department of Obstetrics and Gynecology, Faculty of Medicine, Siriraj Hospital Bangkok, Thailand, Phone: +6624197000 , e-mail: Tuangsit. Wat@mahidol.ac.th
}

abnormality, especially when only one fetus is affected, not only complicates the pregnancy management, but also provokes ethical dilemma when selective feticide is considered for the well-being of the co-twin and the mother. This article is aiming to review various kinds of anomalies that can occur in twin fetuses, as well as the management principles. In this article, the authors have divided fetal anomalies occurring in twin pregnancies into three categories: Discordant anomalies in dichorionic (DC) twins, discordant anomalies in monochorionic (MC) twins, and complicated MC twins. Preterm delivery is not uncommon in multifetal gestations. When one fetus with major anomaly is present in a twin gestation, especially those that cause polyhydramnios, the chance of preterm delivery is even higher. ${ }^{2-4}$

\section{GENETICS OF TWINNING}

Understanding of genetics involved in twinning process is crucial for providing an optimal counseling, followup, and intervention. Dizygotic twinning is the result of fertilization of more than one ovum with more than one spermatozoon, whereas monozygotic twinning is the result of fertilization of one ovum with one spermatozoon. Dizygotic twins are always DC (each fetus has its own amnion, chorion, and placenta), whereas monozygotic twins can be DC (separated amnion, chorion, and placenta), MC diamniotic (separate amnion, shared chorion, and placenta), monoamniotic (shared amnion, chorion, and placenta), or conjoined twins. Chorionicity can be diagnosed with very high accuracy from an early ultrasound. Ultrasound diagnostic features of each types of twinning are shown in Figures 1 to 4 . Fetofetal blood transfusion is a universal phenomenon in MC twins. This intertwin anastomoses can contribute to unique complications of MC twins, as well as affect the method of choice for selective feticide for discordant fetal anomalies.

\section{DISCORDANT ANOMALIES IN DC TWINS}

Fetuses in DC twins do not share placental circulation. The frequency of anomalies in DC twins is thought to be comparable to those occurring in singleton pregnancy. ${ }^{5}$ Discordant fetal anomalies in DC twins can be managed expectantly. Certain fetal aneuploidies or anomalies, such as duodenal obstruction can cause polyhydramnios in the 




Fig. 1: Transabdominal ultrasound image of DC twins at 13 weeks. Note that there are two placentae. The intertwin membrane is thick, and there is chorionic tissue interposing between the amnion leaves, known as lambda $(\lambda)$ sign at the base of the septum

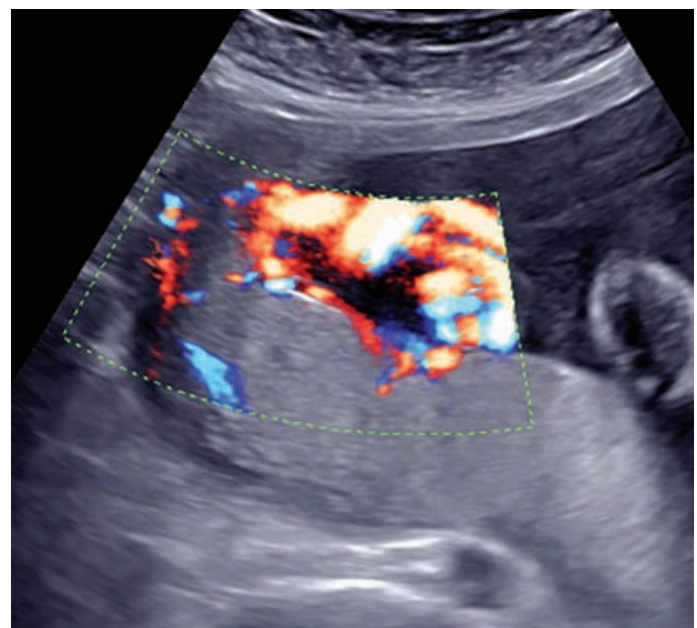

Fig. 3: Transabdominal ultrasound image of monoamniotic twins at 24 weeks. Note that there is single placenta. Insertions of the umbilical cords are very close to each other, and are connected with large bidirectional chorionic anastomoses. Cord entanglement is always found in monoamniotic twins

sac of that anomalous fetus, as shown in Figure 5. This may lead to miscarriage or very premature birth of both fetuses. In this scenario, selective termination/feticide of the anomalous fetus may deem necessary, to protect the well-being of its co-twin. Ultrasound-guide intracardiac injection of cardioplegic substance can be offered in this situation. Either potassium chloride $(\mathrm{KCl})$ or lidocaine is a viable option for this procedure. Complete and permanent cessation of fetal cardiac activity needs to be ascertained before the needle is withdrawn.

\section{DISCORDANT ANOMALIES IN MC TWINS}

When MC twins are complicated with discordant fetal anomalies, the management scheme will be much more



Fig. 2: Transvaginal ultrasound image of $M C$ diamniotic twins at 14 weeks. Note that there is a single placenta. The intertwin membrane is thin. There is no chorionic tissue interposing between the amnion leaves. This is known as T sign, which is visible at the base of the septum

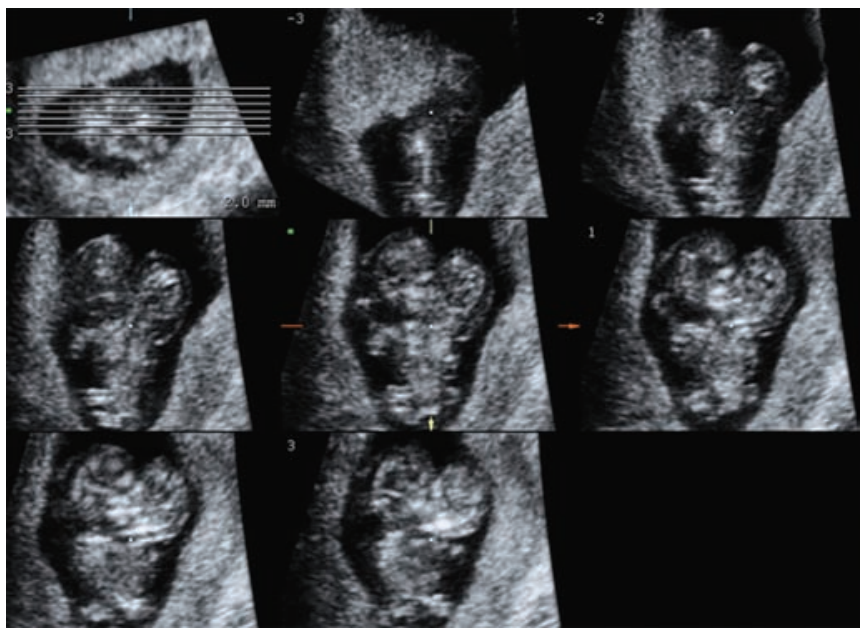

Fig. 4: Tomographic ultrasound imaging (TUI) of thoracoomphalopagous conjoined twins at 11 weeks



Fig. 5: Large chorioangioma found in one placenta of DC twins at 11 weeks. This fetus has thick nuchal translucency compared with its co-twin 


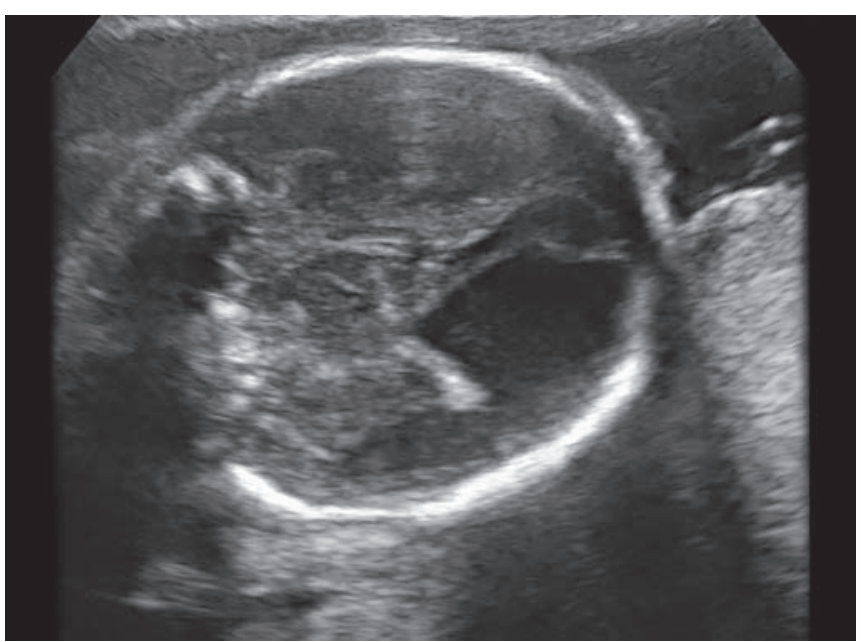

Fig. 6: An axial view of fetal brain at 28 weeks shows focal destruction of cerebral cortex as a result of agonal hypotension. Its MC co-twin demised at 20 weeks



Fig. 8: Transabdominal ultrasound image of radiofrequency ablation. Note that the coagulation is being performed on the intrafetal part of the umbilical cord

complex. If that particular anomaly is associated with polyhydramnios, it can lead to miscarriage or very premature birth of both fetuses. If the anomalous fetus dies, there will be generalized vasodilation, leading to abrupt draining of blood from the live fetus to the demised one, so-called agonal hypotension. This phenomenon will kill approximately $25 \%$ of the co-twin. If survived, the co-twin will stand approximately $25 \%$ chance of significant brain damages and cerebral palsy, as shown in Figure 6.

Therefore, if the anomalous fetus in MC twin pair starts to show ominous signs, umbilical cord occlusion is usually offered to prevent double demise and cerebral palsy of the co-twin. Various techniques of cord occlusion have been described. In utero bipolar diathermy (Fig. 7) and radiofrequency ablation (Fig. 8) of the umbilical cord

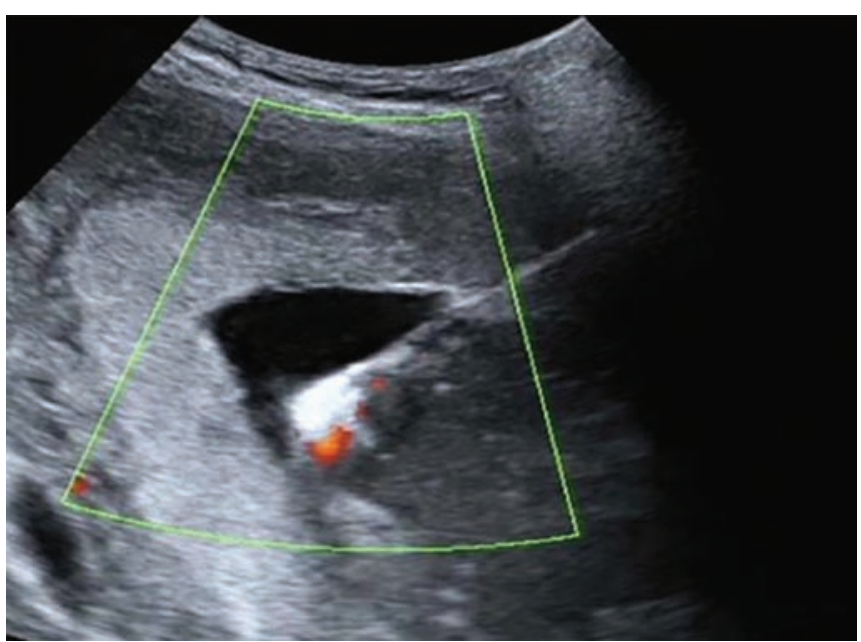

Fig. 7: Transabdominal ultrasound image of in utero bipolar diathermy. This picture was captured during the application of electrical energy. Note the gradually cessation of blood flow within the umbilical cord. Care must be taken during the energy application to prevent unintended thermal injury to its normal co-twin. The coagulation should be repeated until complete cessation of flow is achieved

seem to be the most effective method, whereas injection of absolute alcohol and coil occlusion are associated with higher failure rate. Success rate of cord occlusion with different techniques are shown in Table 1.

Discordant anomalies in MC twins are not an uncommon event. Among these, discordant fetal anencephaly, as shown in Figure 9, is among the most ethical controversies in prenatal management. Detection of discordant fetal anencephaly is usually made early on in gestation due to a wider adoption of fetal aneuploidy screening program. These include the detection of fetal acrania during routine prenatal nuchal translucency scanning in the first trimester, as well as an increased maternal serum alpha-fetoprotein (MS-AFP) in the second trimester serum

Table 1: Success rate of cord occlusion with different techniques

\begin{tabular}{|c|c|c|}
\hline Techniques & $\begin{array}{l}\text { Success rate } \\
\text { (technical/ } \\
\text { clinical) }\end{array}$ & Remarks \\
\hline $\begin{array}{l}\text { Sclerosing substances } \\
\text { (i.e., ethanol) and } \\
\text { embolization (i.e., coil) }\end{array}$ & $33 \%$ & $\begin{array}{l}\text { Recanalization or } \\
\text { migration of coils }\end{array}$ \\
\hline $\begin{array}{l}\text { US or fetoscopic } \\
\text { guided cord ligation }\end{array}$ & $62 \%$ & $\begin{array}{l}\text { PPROM 30\%, technical } \\
\text { difficulties, multiple } \\
\text { ports }\end{array}$ \\
\hline $\begin{array}{l}\text { Monopolar } \\
\text { thermocoagulation }\end{array}$ & $?$ & \\
\hline Laser cord transection & & $\begin{array}{l}\text { Higher failure with more } \\
\text { advanced gestational } \\
\text { age }(>20 \text { wks') }\end{array}$ \\
\hline Bipolar diathermy & $80 \%$ & $\begin{array}{l}\text { Higher failure with more } \\
\text { advanced gestational } \\
\text { age (>20 wks') }\end{array}$ \\
\hline $\begin{array}{l}\text { Radiofrequency } \\
\text { ablation }\end{array}$ & $90 \%$ & $\begin{array}{l}\text { Low chance of } \\
\text { terminating the wrong } \\
\text { fetus }\end{array}$ \\
\hline Harmonic scalpel & ? & Require laparotomy \\
\hline
\end{tabular}




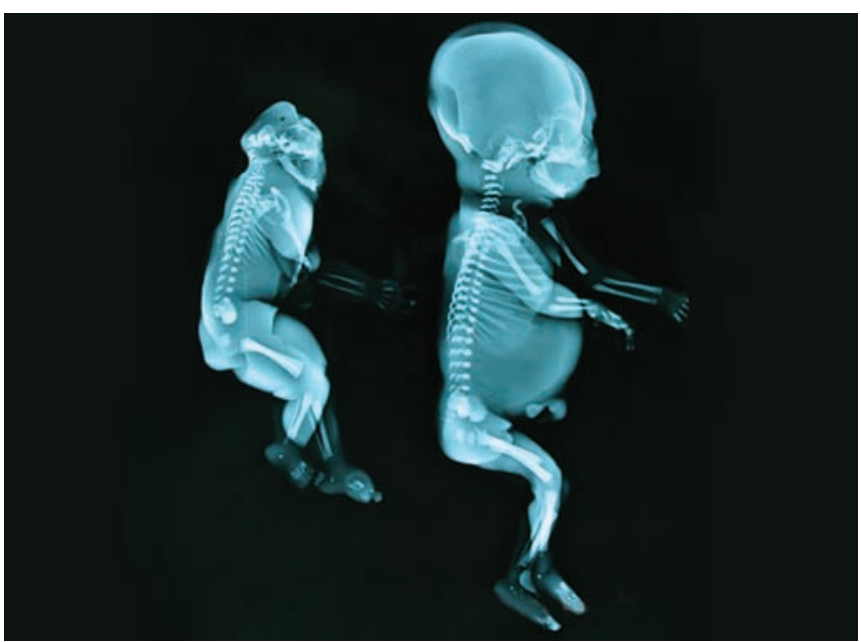

Fig. 9: Radiograph of aborted MC twins (maternal choice) with discordant anencephaly

screening. The discordance of fetal anencephaly is more common in MC than in DC twins. ${ }^{6}$

Fetal acrania has an increased chance of spontaneous demise and polyhydramnios that threaten loss of the whole pregnancy. Discordant fetal acrania arising in DC twins has two different approaches. The first approach is intracardiac injection of $\mathrm{KCl}$ in the second trimester as a prophylactic measure, and the second approach is to offer a serial scanning, and either serial amnioreduction or selective fetocide with intracardiac injection of cardioplegic substances can be offered before the polyhydramnios starts to develop. Selective termination of the fetus with acrania in MC twins has to be performed by cord occlusion, which is more technically demanding. It is still ethically debatable whether to offer this treatment only when polyhydramnios develops or to offer it as a universal prophylaxis. ${ }^{7}$

\section{TWIN REVERSED ARTERY PERFUSION (TRAP) SEQUENCE}

Twin reversed artery perfusion sequence may initially be found during the routine first trimester scanning of the MC twins by lack of placental perfusion of one of the twins (acardiac twin). The "reversal arterial perfusion" of this acardiac mass can be detected by the direction of Doppler waveforms in its two-vessel cord as shown in Figure 10. This can be shown on Doppler ultrasound by reversal of the acardiac twin umbilical arterial blood flow toward the fetus. This is a rare complication of MC twins as a result from an abnormal placental arterial-toarterial anastomosis. There is one normal twin (so-called pump twin), which is smaller and viable, and one acardiac twin, which is larger, amorphous, and nonviable, as shown in Figure 11. The mechanism of acardiac fetus formation is thought to be related to deoxygenated blood



Fig. 10: Twin Reversed Arterial Perfusion (TRAP) sequence. Note the amorphous acardiac mass with polydramnios causing pressure symptoms

pumped from the phenotypically normal fetus preferentially circulating to the upper torso of this hemodynamically disadvantaged fetus. Amorphous malformation is, therefore, restricted only to the upper torso portion.

If left untreated, the perinatal mortality for the pump twin can be high as $50 \%$. This is mostly related to high-output cardiac failure and prematurity. And because the acardiac fetus is universally nonviable, the treatment is focused on the viability of the pump twin by occlusion of either intrafetal or extrafetal portion of the umbilical cord.

\section{CONJOINED TWINS}

Failure of the zygote to completely separate results in physical fusion of the fetuses. Conjoined twins are rare, with an estimated prevalence between 1 in 50,000 and 1 in 200,000. There is a predilection of conjoined twins in Southeast Asia and Africa region. It is also 3 times more common in female fetuses compared to male fetuses. In this era of routine screening of fetal Down syndrome, increasing number of conjoined twins are sonographically diagnosed in the first trimester. Conjoined twins are categorized according to the most vital organs that are shared between the fetuses, as shown in Table 2 .

Possibility of postnatal separation has to be discussed with the parents before expectant management or termination of pregnancy is chosen. Thoracopagus and

Table 2: Organ sharing in various kinds of conjoined twins ${ }^{8}$

\begin{tabular}{lll}
\hline Type & Incidence (\%) & Organs shared \\
\hline Thoracopagus & 40 & Heart, liver, GI \\
Omphalopagus & 34 & Liver, GI \\
Pygopagus & 18 & Spine, GU, lower GI \\
Ischiopagus & 6 & Pelvis, GU, GI, liver \\
Craniopagus & 2 & Brain \\
\hline
\end{tabular}




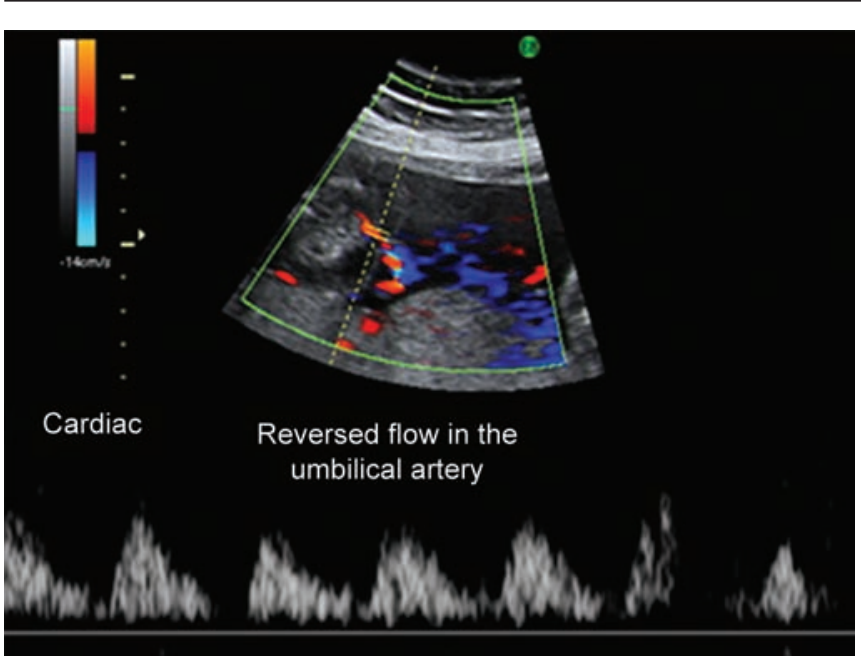

Fig. 11: Color Doppler ultrasound by reversal of the acardiac twin umbilical arterial blood flow toward the acardiac fetus

omphalopagus conjoins may have a small, but realistic, chance of successful postnatal separation. The success is determined by a degree of vital organ (liver and heart) sharing. There are only a handful of technical reports of using various ultrasound techniques and fetal magnetic resonance protocols to predict the postseparation survival. Our team has previously reported the threedimensional (3D) sonoangiographic reconstruction of shared and unshared intrahepatic vasculatures of both fetuses. This information was used in association with other parameters, and the family chose to have an expectant management. The babies were born at term, and they were successfully separated with manageable health impacts. ${ }^{8}$

\section{ETHICAL CONSIDERATIONS OF DISCORDANT FETAL ANOMALIES IN TWINS AND CONCLUSIONS}

Selective feticide of an anomalous twin in discordant twin pregnancy has long been a management option. With wider adoption of routine first trimester screening and the progression in molecular genetic technologies, the diagnosis of a twin gestation discordance for a congenital anomaly is commonly confirmed in the second trimester. After an appropriate counseling, selective termination can then be timely performed under the legal viability gestational age and minimal risk to the mother. Continuous improvements of second trimester terminations, including protocol of choices, indications, timing, and legal gestational age, have evolved over the years, and broad variation does exist, even in different parts of the same country. Ethical issues regarding selective termination have developed significantly and continue to be debated, particularly which forms of fetal anomalies can truly affect the perinatal outcomes of the whole pregnancy. Certainly, sacrificing one's life to save the others is not an easily settled issue.

\section{REFERENCES}

1. Mastroiacovo P, Castilla EE, Arpino C, Botting B, Cocchi G, Goujard J, Marinacci C, Merlob P, Métneki J, Mutchinick O, et al. Congenital malformations in twins: an international study. Am J Med Genet 1999 Mar;83(2):117-124.

2. Alexander JM, Ramus R, Cox SM, Gilstrap LC 3rd. Outcome of twin gestations with a single anomalous fetus. Am J Obstet Gynecol 1997 Oct;177(4):849-852.

3. Nassar AH, Adra AM, Gomez-Marin O, O'Sullivan MJ. Perinatal outcome of twin pregnancies with one structurally affected fetus: a case-control study. J Perinatol 2000 Mar;20(2):82-86.

4. Malone FD, Craigo SD, Chelmow D, D'Alton ME. Outcome of twin gestations complicated by a single anomalous fetus. Obstet Gynecol 1996 Jul;88(1):1-5.

5. Rustico MA, Baietti MG, Coviello D, Orlandi E, Nicolini U. Managing twins discordant for fetal anomaly. Prenat Diag 2005 Sep;25(9):766-771.

6. Sebire NJ, Sepulveda W, Hughes KS, Noble P, Nicolaides KH. Management of twin pregnancies discordant for anencephaly. Br J Obstet Gynaecol 1997 Feb;104(2):216-219.

7. Vandecruys H, Avgidou K, Surerus E, Flack N, Nicolaides $\mathrm{KH}$. Dilemmas in the management of twins discordant for anencephaly diagnosed at $11+0$ to $13+6$ weeks of gestation. Ultrasound Obstet Gynecol 2006 Oct;28(5):653-658.

8. Wataganara T, Sutanthaviboon A, Ngerncham S, Vantanasiri C. Three-dimensional power Doppler in the diagnosis and surgical management of thoraco-omphalopagus conjoined twins. Ultrasound Obstet Gynecol 2008 Aug;32(2):236-237. 